\title{
MENINGKATKAN KEMAMPUAN MENULIS ANGKA 1-3 MELALUI METODE STIMULASI MULTISENSORIS DAN REINFORCEMENT PADA ANAK TUNAGRAHITA SEDANG
}

\author{
Improving the Ability of Writing Numbers using Multisensorical \\ Stimulation and Reinforcement on Moderate Intellectual Disability Child
}

\author{
Nathaniela Esterina ${ }^{1}$, Ikhmahwati Tan Mutiara ${ }^{2}$, Cindy Febriani Lee ${ }^{3}$ \\ ${ }^{12}$ Program Studi Psikologi, Universitas Bunda Mulia
}

Diterima 25 Oktober 2020 / Disetujui 30 Oktober 2020

\begin{abstract}
Every children in Indonesia, including children with special needs, has the same chance and right to pursue education. Intellectual disability children is the condition in which their intelligence experiences obstacles characterized by below-average intelligence and not proficient in social interaction that makes them to experience difficulties in learning and academic abilities such as writing which causes them to lag behind their other friends. The researchers' aim is to improve the intellectual disability children's ability to write numbers 1-3 through multisensory and reinforcement method. The research method is Single Subject Research (SSR) with A-B-A' design (with 3 phases; pre-test, intervention, post-test). The initial of the subject in this research is $G, 5$ years old.
\end{abstract}

Keywords: mental disability, multisensoric stimulation, reinforcement, writing number

\begin{abstract}
ABSTRAK
Setiap anak di Indonesia, termasuk anak berkebutuhan khusus, memiliki kesempatan dan hak yang sama untuk menempuh pendidikan. Anak tunagrahita adalah kondisi dimana kecerdasan anak mengalami hambatan ditandai dengan intelegensi dibawah rata-rata dan tidak cakap dalam interaksi sosial sehingga mengalami kesulitan dalam belajar maupun kemampuan akademis seperti menulis yang akhirnya menyebabkannya tertinggal dengan teman-temannya yang lain. Tujuan yang diharapkan oleh peneliti adalah untuk meningkatkan kemampuan menulis angka 1-3 melalui metode multisensoris dan reinforcement pada anak tunagrahita. Metode yang digunakan dalam penelitian ini adalah Single Subject Research (SSR) dengan desain A-B-A' (dengan tiga tahap yaitu pre-test, intervensi, post-test). Subyek dalam penelitian berinisial $\mathrm{G}$ berusia 5 tahun.
\end{abstract}

Kata kunci: kemampuan menulis angka, reinforcement, stimulasi multisensori, tunagrahita

\section{PENDAHULUAN}

Seluruh anak di dunia terlahir dengan kondisi yang berbeda antara satu sama lain. Hal ini menyebabkan setiap anak memiliki karakteristik yang berbeda, dengan perbedaan tersebut maka setiap anak memiliki kebutuhan yang harus dipenuhi. Namun terdapat anak-anak yang terlahir dengan tidak sempurna sehingga memiliki kebutuhan yang lebih besar dari anak-anak pada umumnya. Anak-anak

\footnotetext{
*Korespondensi Penulis:

${ }^{1}$ nathaniela.esterina@gmail.com
}

inilah yang dikenal sebagai anak berkebutuhan khusus (ABK), salah satu jenis anak berkebutuhan khusus adalah tunagrahita. Badan Pusat Statistik (BPS) tahun 2017 mengungkapkan bahwa dari 264 juta penduduk Indonesia, sebanyak 1,6 juta jiwa $(0.6 \%)$ adalah penyandang cacat, sedangkan populasi anak tunagrahita merupakan yang terbesar dibandingkan dengan anak berkebutuhan khusus lainnya (Redaktur 4, 2018).

Anak tunagrahita adalah kondisi di mana kecerdasan anak mengalami hambatan sehingga tidak mencapai tahap perkembangan yang optimal. Hal tersebut 
Versi Online: http://journal.ubm.ac.id/index.php/psibernetika DOI: 10.30813/psibernetika. v13i2.2383 Hasil Penelitian

ditandai dengan intelegensi dibawah ratarata dan tidak cakap dalam interaksi sosial (Delphie, 2006). Effendi (2006) membagi anak tunagrahita ke dalam tiga kategori yaitu, IQ < 25 disebut sebagai anak tunagrahita berat atau mampu rawat, kemudian IQ 25-50 disebut sebagai anak tunagrahita sedang atau mampu latih, dan IQ 50-75 sebagai anak tunagrahita ringan atau mampu didik. Walaupun anak tunagrahita dikatakan sebagai anak yang memiliki intelegensi dibawah rata-rata, anak tunagrahita masih memiliki hak untuk menempuh dan mendapat pendidikan.

Di Indonesia, pendidikan untuk anak berkebutuhan khusus (ABK) diatur dalam Undang-Undang No. 20 tahun 2003 tentang Sistem Pendidikan Nasional Pasal 5 ayat 2 yang menyatakan bahwa: "Warga negara yang mengalami kelainan fisik, emosional, mental, intelektual dan atau sosial berhak memperoleh pendidikan khusus.". Pasal ini menegaskan bahwa setiap anak di Indonesia termasuk anak berkebutuhan khusus memiliki kesempatan dan hak yang sama untuk menempuh pendidikan di Indonesia. Maka dari itu, pemerintah menyediakan beberapa sarana pendidikan untuk anak-anak berkebutuhan khusus yaitu sekolah luar biasa (SLB).

Anak berkebutuhan khusus seringkali kesulitan dalam belajar dan kemampuan akademis. Dalam hal ini, anak berkebutuhan khusus seringkali tidak bisa menulis angka dan huruf. Murid dengan ABK seringkali harus dibantu guru untuk menulis. Dan seringkali, siswa dengan ABK mudah merasa bosan dengan suasana kelas, sehingga menyebabkannya tertinggal dengan teman-temannya yang lain.

Berdasarkan pada gambaran permasalahan diatas, penulis tertarik untuk meningkatkan kemampuan menulis angka. Dalam melatih menulis angka, penulis akan menggunakan metode multisensoris (VAKT), penulis memilih penggunaan metode multisensoris (VAKT) karena dalam penulisan yang dilakukan oleh Kumilasar, Iswari \& Sumekar (2016), metode ini terbukti efektif dalam meningkatkan kemampuan menulis anak tunagrahita sedang. Metode multisensoris (VAKT - Visual, Audio, Kinestetik dan Taktil) melibatkan dan mengaktifkan seluruh indera yang ada dan meliputi kegiatan-kegiatan yang membutuhkan konsentrasi seperti mendengarkan dan mengucapkan (audio), melihat (visual), menelusuri dan meraba (taktil) dan menulis di awang-awang (kinestetik) (Flemming \& Millis, 1992). Kegiatan yang bervariasi dan melibatkan seluruh sensori dalam pembelajaran diharapkan mampu mempermudah subjek dalam memahami dan mencegah kebosanan pada subjek.

Tujuan dari penelitian ini adalah untuk meningkatkan kemampuan subjek dalam menulis angka 1-3 secara mandiri, karena menulis secara mandiri adalah kegiatan yang sangat sering dilakukan dalam kehidupan sehari-hari. Manfaat dari penelitian ini adalah agar para pengajar di SLB yang menangani anak Tunagrahita mampu memberikan pengajaran yang lebih inovatif, sehingga anak merasa tertarik untuk belajar dan membuat hasil pembelajaran yang lebih efektif.

\section{Metode Multisensoris}

Metode multisensoris adalah metode pembelajaran yang ditemukan oleh dokter Gillingham. Metode ini dapat disebut juga sebagai metode VAKT. Menurut Purnamasari \& Soendari (2018), metode ini dikembangkan oleh Fernald dan Gillingham. Asumsi yang mendasari metode ini adalah bahwa dalam pembelajaran membaca, menulis, dan mengeja kata dipandang sebagai satu rangkaian huruf-huruf.

Metode VAKT adalah metode pembelajaran yang menggunakan seluruh indera yang ada pada anak, agar mampu memfungsikannya sebagai modalitas yang cukup. Dalam metode ini, pembelajaran menggunakan indera penglihatan (visual), indera pendengaran (auditori), indera perabaan (taktil) dan gerakan (kinestetik), sehingga anak akan lebih mudah mengenal bilangan yang akan dipelajarinya. Maulana (2013) dalam penelitiannya menyatakan metode VAKT dapat dikatakan efektif 
Versi Online: http://journal.ubm.ac.id/index.php/psibernetika DOI: 10.30813/psibernetika. v13i2.2383

Hasil Penelitian

apabila digunakan untuk meningkatkan kemampuan menulis permulaan anak kesulitan belajar.

\section{Tunagrahita}

Menurut Kemis \& Ati (2013:1), anak tunagrahita adalah individu yang secara signifikan memiliki tingkat kecerdasan dibawah kecerdasan normal/rata-rata dengan skor IQ sama atau lebih rendah dari 70 , sehingga akan menghambat segala aktivitas kehidupan sehari-hari, dalam berinteraksi dengan sesama, komunikasi dan menerima pembelajaran yang bersifat akademik. Dalam penelitian ini, peneliti akan lebih berfokus kepada anak tunagrahita sedang.

Anak tunagrahita sedang adalah salah satu jenis anak tunagrahita yang memiliki IQ 3651 pada Skala Binet dan 40-54 menurut Skala Weschler (WISC). Anak tunagrahita sedang masih mampu belajar membaca dan menulis secara sosial, namun sulit secara akademis. Mereka dapat didik mengurus diri sendiri, melindungi diri sendiri dari bahaya seperti menghindari kebakaran, berjalan dijalan raya, berlindung dari hujan, dan sebagainya (Apriyanto, 2012:32). Dalam kehidupan sehari-hari, anak tunagrahita sedang memerlukan pengawasan secara terus-menerus

\section{METODE PENELITIAN}

Metode yang digunakan dalam Penelitian ini menggunakan jenis metode penelitian Single Subject Research (SSR) dengan desain A-B-A', yang dilakukan dengan tiga tahapan. Tahapan pertama dilakukan dengan cara mengamati kemampuan awal anak dalam menulis angka 1, 2, dan 3 yang diterapkan melalui observasi pada kondisi awal subyek dan interview dengan orang tua subyek sebelum diberikan intervensi atau yang disebut dengan baseline/pre-test (A). Tahapan kedua dilakukan dengan mengamati peningkatan tingkat kemampuan anak dalam menulis angka 1, 2, dan 3
Jurnal Psibernetika

Vol.13 (No.2) : 100-104. Th. 2020

p-ISSN: 1979-3707

e-ISSN: 2581-0871

menggunakan teknik VAKT dan reinforcement (B). Sedangkan, tahapan ketiga ini adalah pengulangan baseline (post-test) yaitu mengamati kemampuan anak dalam menulis angka 1,2 , dan 3 yang diterapkan melalui observasi pada subyek dan wawancara dengan orang tua subyek setelah diberikan intervensi (A'). Pengamatan ini dilakukan pada seorang anak tunagrahita berinisial $G$ berusia 5 tahun.

\section{HASIL DAN PEMBAHASAN}

Peneliti melakukan intervensi sebanyak lima pertemuan. Pada pertemuan pertama, peneliti melakukan wawancara dengan orang tua dan pre-test terhadap subjek. Pada tahap wawancara ini, orang tua menceritakan gejala-gejala tunagrahita yang dialami oleh sang anak. Peneliti tidak dapat melakukan test IQ dikarenakan intervensi dilakukan secara online. Namun, orang tua menjabarkan bahwa perkembangan sang anak, khususnya dalam berbicara dan menulis terlambat. Ketika pre-test dilakukan, subjek tidak bisa mengenali angka satu, dua ataupun tiga. Hal ini terlihat ketika peneliti meminta subjek mengangkat balok mainan dengan angka 1 , subjek terlihat kebingungan dengan hal tersebut. Subjek juga belum terlalu kuat dalam memegang pensil.

Pada pertemuan kedua, peneliti melakukan intervensi untuk pertama kalinya. Peneliti mengenalkan angka 1 kepada subjek. Pertama-tama, subjek akan diminta untuk memegang balok angka satu. Balok tersebut diberikan oleh orang tuanya. Subjek diminta untuk memegang balok tersebut, dan mencoba untuk menulis berdasarkan balok tersebut. Selain itu, peneliti juga menunjukkan cara menulis angka satu kepada peneliti. Kendala dalam intervensi pertama ini adalah subjek beberapa kali kehilangan fokusnya ketika ada suara kendaraan yang keras ataupun suara lainnya dari luar rumah.

Pada pertemuan ketiga, peneliti melakukan intervensi kedua. Peneliti melakukan review kepada subjek dengan 
Versi Online: http://journal.ubm.ac.id/index.php/psibernetika DOI: 10.30813/psibernetika. v13i2.2383

Hasil Penelitian

meminta subjek menulis angka 1 kembali. Setelah subjek mulai terbiasa dengan angka 1, peneliti mulai mengajarkan angka 2 kepada subjek. Kendala yang didapatkan pada intervensi kedua ini adalah subjek yang kebingungan bagaimana membuat lengkungan pada angka dua. Intervensi kedua ini memiliki durasi waktu yang lebih lama dibandingkan intervensi pertama. Namun, pada akhirnya, subjek berhasil menulis angka dua dengan baik.

Pada pertemuan keempat, peneliti melakukan intervensi ketiga. Peneliti melakukan review kepada subjek dengan meminta subjek menulis angka 1 dan 2 . Subjek sudah terbiasa dengan angka satu, namun masih sedikit kaku ketika diminta menulis angka dua. Setelah pengulangan beberapa kali, subjek bisa menulis angka 1 dan 2 lebih rapi dibandingkan intervensi sebelumnya. Kemudian, peneliti mengajarkan subjek untuk menulis angka 3 . Subjek hampir tidak memiliki kendala pada intervensi ketiga ini, dikarenakan penulisan angka tiga yang mirip dengan angka dua.

Pada pertemuan kelima, peneliti melakukan post-test untuk melihat apakah ada perbedaan sebelum dan setelah melakukan intervensi. Pada post-test ini, subjek diminta untuk mengangkat balok mainan. Misalnya, peneliti meminta subjek mengangkat balok angka 1, 2 dan 3. Setelah itu, peneliti meminta subjek untuk menulis angka 1, 2 dan 3. Pada post-test ini didapatkan hasil bahwa subjek sudah bisa membedakan angka 1,2 , dan 3 , serta sudah bisa menulis angka 1 sampai 3 .

Tabel 1. Perbandingan pre-test dan post-test

\begin{tabular}{lccl}
\hline Perilaku & $\begin{array}{c}\text { Pre- } \\
\text { test }\end{array}$ & $\begin{array}{c}\text { Post- } \\
\text { test }\end{array}$ & Simpulan \\
\hline $\begin{array}{l}\text { Menulis } \\
\text { angka } 1\end{array}$ & 0 & 1 & $\begin{array}{l}\text { Terjadi } \\
\text { peningkatan }\end{array}$ \\
$\begin{array}{l}\text { Menulis } \\
\text { angka } 2\end{array}$ & 0 & 1 & $\begin{array}{l}\text { Terjadi } \\
\text { peningkatan }\end{array}$ \\
$\begin{array}{l}\text { Menulis } \\
\text { angka 3 }\end{array}$ & 0 & 1 & $\begin{array}{l}\text { Terjadi } \\
\text { peningkatan }\end{array}$ \\
\hline $\begin{array}{l}* 0 \text { tidak } \\
\text { dimaksud }\end{array}$ & mampu & melakukan & perilaku yang \\
$* 1=$ mampu melakukan perilaku yang dimaksud
\end{tabular}

$$
\begin{array}{r}
\text { Vol.13 (No.2) : 100-104. Th. } 2020 \\
\text { p-ISSN: 1979-3707 } \\
\text { e-ISSN: 2581-0871 }
\end{array}
$$

Dalam proses intervensi orang tua subjek secara aktif terlibat membantu proses pembelajaran. Lalu, pada saat intervensi, setiap subjek berhasil mengikuti instruksi, peneliti akan memberikan pujian sebagai bentuk reinforcement untuk subjek. Hal ini dinilai berhasil, dikarenakan setiap subjek mendapatkan pujian, ia akan tersenyum dan meminta orang tuanya untuk membantunya menulis lagi hingga ia bisa menulis sendiri. Dan di akhir intervensi, peneliti memberikan reinforcement berupa barang agar subjek semakin semangat untuk belajar menulis angka-angka selanjutnya, dan semangat untuk sekolah di kemudian hari.

Temuan penelitian ini sejalan dengan penelitian sebelumnya, yaitu penelitian yang dilakukan oleh Kumilasari (2014) mengenai meningkatkan kemampuan menulis huruf vokal (a, e, i, o, u) pada anak tunagrahita.

\section{SIMPULAN}

Penelitian ini menyimpulkan bahwa teknik multisensoris VAKT (visual, audio, kinestetik, taktil) dan reinforcement dapat meningkatkan kemampuan menulis angka 1 sampai 3 pada anak tunagrahita. Teknik multisensoris VAKT yang digunakan berupa pemberian contoh melalui gambar (visual), memberikan arahan (audio), mengajak anak tunagrahita dalam mencontohkan tulisan (kinestetik), dan memberikan alat agar anak tunagrahita juga mampu memanfaatkan indra peraba guna mendukung pemahaman dalam belajar (taktil).

Adapun penelitian ini menyarankan penggunaan teknik VAKT (visual, audio, kinestetik, dan taktil) dalam pembelajaran anak tunagrahita. Tenik VAKT digunakan sebagai stimulus multisensoris yang melibatkan aktif semua indra anak tunagrahita. Tak hanya itu, peneliti juga menyarankan penggunaan reinforcement upaya memperkuat perilaku yang diinginkan. 
Versi Online: http://journal.ubm.ac.id/index.php/psibernetika DOI: 10.30813/psibernetika. v13i2.2383

Hasil Penelitian

\section{DAFTAR PUSTAKA}

Afiffah, Nur \& Tjutju Soendari. (2017). Meningkatkan kemampuan berbicara pada anak tunagrahita sedang melalui media gambar di SLB B-C YPLAB Kota Bandung. Jurnal Asesmen dan Intervensi Anak Berkebutuhan Khusus. 18(1). 47-54.

Apriyanto, Nunung. (2012). Seluk-beluk tunagrahita dan strategi pembelajarannya. Jogjakarta: Javalitera.

Delphie, B. (2006) Pembelajaran anak tunagrahita. Bandung: PT Refika Aditama.

Effendi, M. (2006). Pengantar psikopedagogik anak berkelainan. Jakarta: PT Bumi Askara.

Harian Terbit. (2018). Hetifah: data BPS, makin banyak anak berkebutuhan khusus. Diambil dari March 17, 2019, from https://harianterbit.co/ 2018/04/10/hetifah-data-bpsmakin-banyak-anak-berkebutuhankhusus/

Kemis \& Ati. (2013). Pendidikan anak berkebutuhan khusus tunagrahita. Jakarta: Luxima.

Kumilasari, D. (2016). Meningkatkan kemampuan menulis huruf vokal (a, i, u, e, o) melalui metode VAKT bagi anak tunagrahita sedang di SLB Talawi Sawahlunto. Jurnal Penulisan Pendidikan Khusus. 5(2). 24-37.

Maulana, S. (2013). Efektifitas metode VAKT untuk meningkatkan kemampuan menulis permulaan bagi anak kesulitan belajar. Jurnal Ilmiah Pendidikan Khusus, 2(3), 222-233.

Miltenberger, R.G. (2012). Behavior modification; principles and procedures $\left(5^{\text {th }}\right.$ Ed.). Boston: Cengage Learning.

Purnamasari, P., \& Tjutju S. (2018). Metode VAKT untuk pembelajaran membaca permulaan anak tunagrahita ringan. Jurnal Asesmen
Vol.13 (No.2) : 100-104. Th. 2020 p-ISSN: 1979-3707

e-ISSN: 2581-0871

Dan Intervensi Anak Berkebutuhan Khusus. 19(1), 25-31.

Rahman, A.A. (2017). Sejarah psikologi: Dari klasik hingga modern. Depok: PT RajaGrafindo Persada.

Undang-Undang Republik Indonesia Nomor 20 Tahun 2003 Sistem Pendidikan Nasional. 8 Juli 2003. Lembaran Negara Republik Indonesia Tahun 2003 Nomor 4301. Jakarta.

Yusuf, M. (2005). Pendidikan bagi anak dengan problem belajar. Jakarta: Depdiknas.

Zainuddin. (1991). Materi pokok bahasa dan sastra Indonesia. Jakarta: Rineka Cipta. 